\title{
Verhältnismäßigkeit als Rationalitätskontrolle
}

Eine rechtsempirische Studie verfassungsgerichtlicher Rechtsprechung zu den Freiheitsgrundrechten

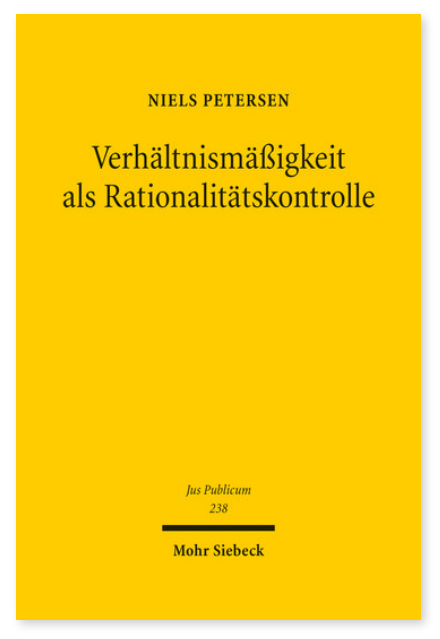

2015. XIV, 334 Seiten. JusPubl 238

ISBN 978-3-16-153564-2

DOI 10.1628/978-3-16-153564-2

eBook PDF $114,00 €$
Verfassungsgerichtsbarkeit befindet sich auf der Schnittstelle zwischen Recht und Politik. Vielen Verfassungsgerichten wird der Vorwurf gemacht, politischen Aktivismus zu betreiben. Als eines der Hauptinstrumente eines solchen

verfassungsgerichtlichen Aktivismus wird - zumindest in der deutschen Diskussion - die Abwägung im Rahmen der Verhältnismäßigkeit ausgemacht. Diese sei juristisch nicht rationalisierbar und eröffne Verfassungsrichtern daher politische Handlungsspielräume. Niels Petersen spürt dieser These nach. Zu diesem Zweck unterzieht er die Rechtsprechung des Bundesverfassungsgerichts, des südafrikanischen Verfassungsgerichts und des kanadischen Supreme Court einer empirischen Untersuchung. Er kommt zu dem Ergebnis, dass die untersuchten Gerichte neben dogmatischen auch institutionellen Schranken unterliegen und sich daher bei der Abwägung eher zurückhalten. Verhältnismäßigkeit wird vielmehr als Instrument zur Rationalitätskontrolle des Gesetzgebers verstanden.

Niels Petersen Geboren 1978; Studium der Rechts- und Sozialwissenschaften in Münster, Genf und New York; 2008 Promotion zum Dr. iur.; Wissenschaftlicher Referent am Max-Planck-Institut zur Erforschung von Gemeinschaftsgütern; Inhaber des Lehrstuhls für Öffentliches Recht einschließlich Völker- und Europarecht der Universität Münster.
Jetzt bestellen:

https://mohrsiebeck.com/buch/verhaeltnismaessigkeit-als-rationalitaetskontrolle-9783161535642?no_cache=1 order@mohrsiebeck.com

Telefon: $+49(0) 7071-923-17$

Telefax: $+49(0) 7071-51104$ 